\title{
Eating Behaviors of Postoperative Esophageal Cancer Patients During the First Year After Surgery
}

\author{
Yukina Ueda* and Masami Chujo $\uparrow$ \\ *Department of Palliative care center nurse, Shimane University hospital, Izumo 693-8503, Japan and †Department of Adult and \\ Elderly Nursing, School of Health Science, Tottori University Faculty of Medicine, Yonago 683-8503, Japan
}

\begin{abstract}
Background The objective of this study was to identify the eating behaviors of patients from 3 months onwards after esophageal surgery. The study was conducted on patients who had been on an oral diet for more than 3 months after the surgery.
\end{abstract}

Methods Data were collected through interviews and analyzed by a qualitative inductive method based on the Grounded Theory Approach.

Results The results of the analysis revealed that postoperative esophageal cancer patients go through the following three stages in respect of their eating behavior during the first year after surgery: i) Get used to swallowing, ii) Learning how to cope with the symptoms occurring during eating, by failing and succeeding repeatedly, and iii) building self-management skills in terms of eating behaviors. These were identified as the process through which the patients develop their eating behaviors during the first year after surgery.

Conclusion The patients first faced the reality of the underlying issue, namely, difficulty in eating after the surgery, with the feeling that they experienced during swallowing in the process of eating. However, they had no choice but to accept the reality and make efforts to devise practical eating behaviors through experience. Then, eventually, they learned that self-management is necessary not only for maintaining a stable eating behavior, but also for sustaining their lives. In the longterm post-operative patient's acquisition of new eating habits, medical staff look back and share their experiences so that they can recognize their altered body without being discouraged. However, it is necessary to continue to support them even after they discharge from the hospital by accepting difficulties in eating behavior.

Key words cancer patient; eating behavior; esophageal cancer

In the standard treatment for esophageal cancer, surgical

Corresponding author: Masami Chujo, RN, PhD

chujo@tottori-u.ac.jp

Received 2020 April 27

Accepted 2020 June 25

Online published 2020 August 20 resection is the first-line radical treatment for stages I to III of the disease. ${ }^{1}$ Due to the high risk of lymph node metastasis, lymphadenectomy is also routinely performed. ${ }^{2}$ This may damage the recurrent laryngeal nerve function for a prolonged period after surgery, inevitably affecting eating and swallowing functions. ${ }^{3-5}$

Postoperative esophageal cancer patients are well known to be at a high risk of suffering from eating and swallowing difficulties. ${ }^{6}$ More specifically, patients may experience the following symptoms: feeling of food being stuck in the throat, decreased dietary intake, weight loss, early satiety, and regurgitation. ${ }^{7}$ Owing to these symptoms, they find that they have to make a tremendous effort to eat. ${ }^{8}$ It is a factor of difficulty to be forced to improve eating habits after surgery. ${ }^{9}$ It has been reported that these patients find it difficult to change their eating and swallowing habits, and that, therefore, the need to eat imposes a mental burden on the patients. ${ }^{10}$ According to one report, patients often find that their postoperative eating problems are more serious than they had expected before the surgery. ${ }^{11}$ Furthermore, it has been reported that postoperative esophageal cancer patients are often discharged from the hospital after surgery before their eating function has recovered adequately. ${ }^{8}$ Therefore, it is inevitable that the patients suffer from eating problems resulting from the functional symptoms even after hospital discharge.

According to one report, the process of recovery from eating difficulties in postoperative esophageal cancer patients takes a long time, with establishment of stable eating behaviors often taking more than 1 year after the surgery. ${ }^{12}$ Previously reported studies have identified the difficulties faced by the patients during this recovery process, particularly difficulties in related to lifestyle, living environment, emotional aspects of eating, ${ }^{13}$ reestablishing eating patterns, ${ }^{12}$ and in the lifestyle modification process in postoperative esophageal cancer patients. ${ }^{10}$ Thus, studies have been conducted on the continuous nursing support needed for living in general, including symptom assessment, how to enable patients to cope with difficulties, and provision of appropriate psychological and social support. Since there have been no concrete studies on eating behaviors and interventional methods focusing only on eating 
behaviors, the authors conducted this investigation in an attempt to identify effective nursing support for postoperative esophageal cancer patients.

The aim of this study was to identify the eating behaviors of postoperative esophageal cancer patients during the first year after surgery, as the tentative period required for a stable eating behavior to be established in these patients.

\section{MATERIALS AND METHODS Definitions of terms}

"Eating behaviors" is defined in this study as "postoperative eating conditions differing from those before surgery in esophageal cancer patients, as well as newly established eating methods, modifications and behaviors."

\section{Methodology}

\section{Study subjects}

i) Patients diagnosed with primary thoracic esophageal cancer and informed of the diagnosis, ii) underwent esophageal reconstruction with lymphadenectomy, iii) received an oral diet for more than 3 months after surgery, iv) could communicate verbally, v) could eat on their own, vi) were allowed to participate in the study by their primary care physicians, vii) provided informed consent for participation in this study.

\section{Survey period}

August to October 2017

\section{Study design}

In this study, we used the grounded theory approach (GTA) to generate our own theory of the mechanism by which the phenomenon based on the experience of the patient occurs. ${ }^{10}$ In qualitative research, the data that is the experience of the patient is conceptualized, and the theory is generated by relating the concepts. GTA analyzes by focusing on the subordinate concept consisting of properties and dimensions to raise the abstraction level, but the work method of unitization is clear and easy for others to interpret, and when increasing the abstraction level research bias is also low risk.

\section{Data collection method}

An interview guide was created with reference to previous research. ${ }^{11}$ We conducted interviews using a semistructured interview method in a private room for about 30 minutes per person. Consideration was given so that the subject could freely talk about food intake eating behaviors when the meal started immediately after the operation, physical symptoms, coping methods, and about their thoughts. For patients who provided consent, the interview contents were recorded on an integrated circuit (IC) recorder.

With the permission of the study subjects, basic information about the patients was collected from their medical records and nursing records. Information includes age, disease name, surgical procedure, date of treatment, date of resumption of oral intake, and clinical course of treatment.

\section{Analysis method}

In this study, the eating behaviors of postoperative esophageal cancer patients during the first year after surgery were analyzed based on the data obtained, ensuring that there were no deviations from the information obtained from the study subjects. In reference to the analysis method of GTA, the analysis was carried out as follows: i) a verbatim record was generated using all the data obtained from the first patient and segmented the data based on the semantic content, and ii) from the segmented data, the properties that would become the section or point of view and the dimensions that show how they look when viewed from that property were extracted, and code name was given based on those. We made sure that they were returned to the original segment after assignment of each code, and confirmed that the code was consistent with the content of the text iii) from all the data, data exclusively related to the eating behaviors of the subjects during the first year after resumption of oral intake after surgery were extracted, the codes were sorted into categories, and a name was assigned to each category iv) after assigning category names, we returned to the segmented data, and confirmed that the component category names were consistent with the content of the text v) based on analytical results and theoretical comparisons, theoretical sampling was performed to select the target audience, examine the question content, and collect many properties and dimensions. Based on this, the following data were collected, and steps i) to iv) were repeated. When no new category emerged (when categorization had reached saturation) in the ongoing analysis and data collection process, the data collection was discontinued vi) the categories of shared meanings were classified by phenomenon, to increase the level of extraction; vii) from the extracted categories, a category relationship diagram was created viii) the category relationship diagram was explained using the concept and finally, ix) in the process of analysis, in order to improve reliability and validity, the analysis was conducted after repeated discussions with collaborators who were experienced in qualitative research on cancer nursing. 


\section{Ethical considerations}

The researcher asked the candidate study subjects to obtain a referral from their primary care physicians. For the patients selected as eligible, the researcher explained, in writing, the aims and methodology of the study, that the patients had the freedom to provide consent for participation or not and also the freedom to withdraw consent for/from the study, that their personal information would be protected, that they would not face any/minimal disadvantage if they chose not to participate, about the methods of storage/management and shredding and muting of all data after study completion, about the fact that the use of the data would be restricted to this study, about the researchers intention to review the patients' medical records, and publication of the study results. Then, the researcher obtained informed consent in writing from the patients.

This study was conducted with the approval of the Ethics Review Committee of Tottori University Faculty of Medicine (approval number 1707A070).

\section{RESULTS}

\section{Summary of the study subjects' characteristics}

We selected 12 study subjects, including 9 men and 3 women. At the end of the interview with 10 subjects, it was judged that the theoretical saturation had been reached. However, in order to confirm the theoretical saturation, two additional subjects were subsequently interviewed. The subjects ranged in age from 50 to 80 years, with a mean age of 70.0 years. A summary of the study subjects' characteristics is shown in Table 1.

\section{Summary of interview}

Each subject underwent one interview session lasting from 25 to 60 minutes ( 34 minutes on average). The total duration for all interviews was 434 minutes.

\section{Eating behaviors of postoperative esophageal can- cer patients during the first year after surgery Analysis results}

Analysis of the data on the eating behaviors of postoperative esophageal cancer patients during the first year after surgery yielded 57 codes. Ultimately, the data were divided into 23 subcategories, 9 categories and 3 core categories (Table 2). The process-driven core categories are described below. The core categories are denoted by [ ], categories are denoted by \{\} , and subcategories are denoted by $<>$. The phrases within quotes are those that were directly obtained from the subject interviews, but were supplemented with additional words within (), as needed, to allow easier understanding. The notation in parentheses at the end of the sentence indicates the target person shown in Table 1. Using the categories and subcategories, a relationship diagram was created to explain the phenomena (Fig. 1).

The analysis of the eating behaviors of postoperative esophageal cancer patients during the first year after surgery revealed the involvement of the following processes in the development of eating behaviors:

i) Stage $1-$ [Get used to swallowing]

The study subjects noticed speech impairment and changes in swallowing after surgery. Therefore, they were Ingredients that can be swallowed - Repeat trial and error in the recipe\}, as they attempted to resume eating. These behaviors reflect the efforts of the patients to consume their meals, taking into consideration their own specific circumstances, desperately trying to get used to their new swallowing pattern, taking into account the types of meals that they could eat, how to cook them and their nutritive values, as described in the subcategories.

$<$ Eating, paying attention to what types of meals are easier to eat $>,<$ Selecting and preparing foods, paying attention to the cooking methods and calories>, to match their own daily conditions \{Limited to what you can swallow rather than choosing what to eat $\}$ was derived from $<$ To eat whatever I want to eat $>$ when the subjects attempted to find foods that were easier to swallow, and $<$ What I can eat is limited $>$ when they selected foods taking into account their own tastes and checked what foods were easier/more difficult to swallow.

Their behaviors reflected their desperate efforts to consume food while becoming accustomed to the difficulties in swallowing that they faced for the first time after they resumed eating.

"Well, (as I eat,) I feel that (food) goes down slowly into my stomach. This makes me feel like it is okay, it is fine. (H)"; "I am trying to eat a little bit of what I want to eat. It is not because my taste has changed. It is no longer a choice, what I can eat is limited. (L)"

ii) Stage 2 [Learning how to cope with the symptoms occurring during eating, by failing and succeeding repeatedly]

The study subjects experienced various symptoms after the resumed eating after the surgery. They had a harder time with regard to their eating behaviors than they had expected before the surgery, saying that $<$ The trouble with eating was such that one could not imagine it without actually experiencing it $>$. This experience led them to \{Develop eating behaviors through actual experiences\}. They also identified the following precautions that they needed to take through their experiences of eating meals and learned how to adopt them: <The amount I can eat is always the same, regardless of my 
Table 1. Overview of the target audience

\begin{tabular}{|c|c|c|c|c|c|c|c|}
\hline $\begin{array}{l}\text { Tar- } \\
\text { get }\end{array}$ & Sex & Age & Disease name & Stage & Technique & Reconstruction route & $\begin{array}{c}\text { Period from } \\
\text { meal start }\end{array}$ \\
\hline A & $\mathrm{M}$ & $70 \mathrm{~s}$ & $\begin{array}{l}\text { Mid-thoracic } \\
\text { esophageal cancer }\end{array}$ & III & $\begin{array}{l}\text { Subtotal esophageal extrac- } \\
\text { tion } \\
\text { Remnant gastrectomy } \\
\text { 3-region lymphadenectomy } \\
\text { Cholecystectomy } \\
\text { Cervical esophagus, jejunos- } \\
\text { tomy }\end{array}$ & $\begin{array}{l}\text { Pedicled jejunum in front of the chest } \\
\text { wall }\end{array}$ & $\begin{array}{l}1 \text { year } \\
7 \text { months }\end{array}$ \\
\hline B & $\mathrm{M}$ & $70 \mathrm{~s}$ & $\begin{array}{l}\text { Barrett's } \\
\text { esophageal cancer }\end{array}$ & I & $\begin{array}{l}\text { Thoracic esophagectomy } \\
\text { 3-region lymphadenectomy } \\
\text { Cholecystectomy }\end{array}$ & $\begin{array}{l}\text { Retrosternal route gastric tube recon- } \\
\text { struction }\end{array}$ & $\begin{array}{c}8 \text { year } \\
7 \text { months }\end{array}$ \\
\hline $\mathrm{C}$ & M & $60 \mathrm{~s}$ & $\begin{array}{l}\text { Mid-thoracic } \\
\text { esophageal cancer }\end{array}$ & II & $\begin{array}{l}\text { Subtotal esophageal extrac- } \\
\text { tion } \\
\text { 3-region lymphadenectomy }\end{array}$ & $\begin{array}{l}\text { Reconstruction of the gastric tube in } \\
\text { the posterior sternum }\end{array}$ & $\begin{array}{l}4 \text { year } \\
5 \text { months }\end{array}$ \\
\hline $\mathrm{D}$ & $\mathrm{M}$ & $70 \mathrm{~s}$ & $\begin{array}{l}\text { Mid-thoracic } \\
\text { esophageal cancer }\end{array}$ & I & $\begin{array}{l}\text { Subtotal esophageal extrac- } \\
\text { tion } \\
\text { 3-region lymphadenectomy }\end{array}$ & $\begin{array}{l}\text { Retrosternal route gastric tube recon- } \\
\text { struction }\end{array}$ & $\begin{array}{l}1 \text { year } \\
8 \text { months }\end{array}$ \\
\hline $\mathrm{E}$ & $\mathrm{M}$ & $70 \mathrm{~s}$ & $\begin{array}{l}\text { Mid-thoracic } \\
\text { esophageal cancer }\end{array}$ & II & $\begin{array}{l}\text { Subtotal esophageal extrac- } \\
\text { tion } \\
\text { 3-region lymphadenectomy }\end{array}$ & $\begin{array}{l}\text { Retrosternal route gastric tube recon- } \\
\text { struction }\end{array}$ & $\begin{array}{l}7 \text { year } \\
2 \text { months }\end{array}$ \\
\hline $\mathrm{F}$ & $\mathrm{M}$ & $70 \mathrm{~s}$ & $\begin{array}{l}\text { Mid-thoracic } \\
\text { esophageal cancer }\end{array}$ & I & $\begin{array}{l}\text { Thoracic esophagectomy } \\
\text { 3-region lymphadenectomy } \\
\text { Cholecystectomy }\end{array}$ & $\begin{array}{l}\text { Retrosternal route jejunal recon- } \\
\text { struction }\end{array}$ & $\begin{array}{c}4 \text { year } \\
2 \text { months }\end{array}$ \\
\hline G & $\mathrm{F}$ & $70 \mathrm{~s}$ & $\begin{array}{l}\text { Mid-thoracic } \\
\text { esophageal cancer }\end{array}$ & I & $\begin{array}{l}\text { Subtotal esophageal extrac- } \\
\text { tion } \\
\text { 3-region lymphadenectomy }\end{array}$ & $\begin{array}{l}\text { Reconstruction of the gastric tube in } \\
\text { the posterior sternum }\end{array}$ & $\begin{array}{l}1 \text { year } \\
4 \text { months }\end{array}$ \\
\hline $\mathrm{H}$ & $\mathrm{F}$ & $50 \mathrm{~s}$ & $\begin{array}{l}\text { Mid-thoracic } \\
\text { esophageal cancer }\end{array}$ & III & $\begin{array}{l}\text { Subtotal esophageal extrac- } \\
\text { tion } \\
\text { 3-region lymphadenectomy }\end{array}$ & $\begin{array}{l}\text { Retrosternal route gastric tube recon- } \\
\text { struction }\end{array}$ & $\begin{array}{l}2 \text { year } \\
4 \text { months }\end{array}$ \\
\hline I & M & $60 \mathrm{~s}$ & $\begin{array}{l}\text { Lower thoracic } \\
\text { esophageal cancer }\end{array}$ & II & $\begin{array}{l}\text { Subtotal esophageal extrac- } \\
\text { tion } \\
\text { 3-region lymphadenectomy }\end{array}$ & $\begin{array}{l}\text { Reconstruction of the gastric tube in } \\
\text { the posterior sternum }\end{array}$ & $\begin{array}{l}4 \text { year } \\
6 \text { months }\end{array}$ \\
\hline $\mathrm{J}$ & $\mathrm{M}$ & $50 \mathrm{~s}$ & $\begin{array}{l}\text { Lower thoracic } \\
\text { esophageal cancer }\end{array}$ & III & $\begin{array}{l}\text { Subtotal esophageal extrac- } \\
\text { tion } \\
\text { 3-region lymphadenectomy }\end{array}$ & $\begin{array}{l}\text { Retrosternal route gastric tube recon- } \\
\text { struction }\end{array}$ & $\begin{array}{l}1 \text { year } \\
6 \text { months }\end{array}$ \\
\hline K & M & $70 \mathrm{~s}$ & $\begin{array}{l}\text { Mid-thoracic } \\
\text { esophageal cancer }\end{array}$ & III & $\begin{array}{l}\text { Subtotal esophageal extrac- } \\
\text { tion } \\
\text { 3-region lymphadenectomy }\end{array}$ & $\begin{array}{l}\text { Reconstruction of the gastric tube in } \\
\text { the posterior sternum }\end{array}$ & 1 year \\
\hline $\mathrm{L}$ & $\mathrm{F}$ & $80 \mathrm{~s}$ & $\begin{array}{l}\text { Mid-thoracic } \\
\text { esophageal cancer }\end{array}$ & II & $\begin{array}{l}\text { Subtotal esophageal extrac- } \\
\text { tion } \\
\text { 3-region lymphadenectomy }\end{array}$ & $\begin{array}{l}\text { Retrosternal route gastric tube recon- } \\
\text { struction }\end{array}$ & 10 months \\
\hline
\end{tabular}

F, female; M, male.

desire to eat, so I determine how much to eat by the apparent size and objective volume of the food. $><$ I have learned how to deal with when food gets stuck in the throat. $><$ To eat at my own pace without pressure on how quickly I finish in time to keep up with others> $<$ Determined carefully the amount of one bite and the amount to swallow $><$ I try to chew well, but as a matter of fact, I swallow before I realize $>$ and $<$ When taking medicines, I swallow one tablet at a time, to ensure that each one tablet has passed down the throat, to prevent accidental mis swallowing $>$. This led to \{Confirm through meal intake and acquire cautions and coping strategies\}.

This behavior also indicated their $<$ Trying to change their original eating behavior $>$. In addition, they also learned \{To try to identify my own postures and 
Table 2. Eating behavior of patients with esophageal cancer one year after surgery

Core category Category

(1) Get used to Ingredients that can be swallowed $\bullet$ Repeat trial and error in the recipe

Subcategory

Code

Eating, paying attention to what

types of meals are easier to eat

Selecting and preparing foods, paying attention to the cooking methods and calories

Limited to what you
can swallow rather than
choosing what to eat

To eat whatever I want to eat

What I can eat is limited swallowing

I was thick at the beginning of the meal

Gradually change the form according to one's condition

Think easy-to-eat recipes

Dietary adjustment and intake considering calories

\section{Eat what you like}

Eat as much as you can

What can be eaten is limited rather than taste

Eating and vomiting doesn't mean that everything isn't nutritious

(2) Learning Confirm through meal The amount I can eat is always how to cope intake and acquire with the symp- cautions and coping toms occurring strategies during eating, by failing and succeeding repeatedly

The amount that can be eaten has decreased the same, regardless of my desire to eat, so I determine how much to eat by the apparent size and objective volume of the food.

How much you eat depends on what you eat

I have a desire to eat, but I do not increase because I decide the amount considering the symptoms.

I'm willing to eat, but I can't actually eat

If you want to eat, you can eat, but you can't
Increase the number of meals or eat between meals to compensate for the small amount

I started to eat properly

I have learned how to deal with when food gets stuck in the throat.

To eat at my own pace without Eat slowly over time without being disturbed by the pace pressure on how quickly or finish of others

in time to keep up with others

Eat one meal more slowly than when healthy

You may lose motivation to eat over time

I can't eat fast

I seldom go out because of the amount and pace of eating out

I can't eat when I'm with people

Do at your own pace, without competing with healthy people

Determined carefully the amount Determine how much to swallow in your mouth of one bite and the amount to swallow

Make the bite small

I try to chew well, but as a matter Chew well and swallow of fact, I swallow before I realize

Harder than softer ones can chew better and eat May swallow unknowingly

Trying to change their original eating behavior

Taking the drug while having the core that the drug has passed through the throat

Be cautious because of fear of oral aspiration and reflux

When taking medicines, I swal- I knew that I was going to eat just as I was before low one tablet at a time, to ensure that each one tablet has passed down the throat, to prevent acThere is an understanding of food intake, but it is not possible 


\section{Table 2-Continued}

\begin{tabular}{|c|c|c|c|}
\hline Core category & Category & Subcategory & Code \\
\hline \multirow{13}{*}{$\begin{array}{l}\text { (2) Learn- } \\
\text { ing how to } \\
\text { cope with the } \\
\text { symptoms } \\
\text { occurring } \\
\text { during eating, } \\
\text { by failing and } \\
\text { succeeding } \\
\text { repeatedly }\end{array}$} & \multirow{4}{*}{$\begin{array}{l}\text { When eating out, I se- } \\
\text { lect how to eat or what } \\
\text { to eat depending on } \\
\text { the person I eat with, } \\
\text { and try not to cause } \\
\text { trouble at restaurants }\end{array}$} & \multirow{2}{*}{$\begin{array}{l}\text { Change how you eat and what } \\
\text { you eat depending on who goes } \\
\text { out to eat }\end{array}$} & Choose people to go out to eat \\
\hline & & & $\begin{array}{l}\text { Change how to eat or choose what to eat depending on } \\
\text { who goes out to eat }\end{array}$ \\
\hline & & \multirow[t]{2}{*}{ I hate to bother the shop } & How to vomit when eating out \\
\hline & & & May disturb the shop \\
\hline & \multirow{4}{*}{$\begin{array}{l}\text { To try to identify my } \\
\text { own postures and be- } \\
\text { haviors that facilitate } \\
\text { digestion }\end{array}$} & \multirow{2}{*}{$\begin{array}{l}\text { Lying as a way to promote post- } \\
\text { meal food and digestion }\end{array}$} & I'm lying right after eating \\
\hline & & & Lying down as a way to encourage digestion \\
\hline & & \multirow[t]{2}{*}{$\begin{array}{l}\text { Devise eating postures and ac- } \\
\text { tions after eating }\end{array}$} & $\begin{array}{l}\text { After eating, don't lie down or move around to help diges- } \\
\text { tion }\end{array}$ \\
\hline & & & $\begin{array}{l}\text { Be careful when eating in the tatami room, as it may get } \\
\text { stuck in your body }\end{array}$ \\
\hline & \multirow[t]{2}{*}{$\begin{array}{l}\text { Develop eating be- } \\
\text { haviors through actual } \\
\text { experiences }\end{array}$} & \multirow[t]{2}{*}{$\begin{array}{l}\text { The trouble with eating was such } \\
\text { that one could not imagine it } \\
\text { without actually experiencing it }\end{array}$} & $\begin{array}{l}\text { There were a lot of things I learned from actual experience } \\
\text { I'm looking for a way to deal with it through actual experi- } \\
\text { ence }\end{array}$ \\
\hline & & & $\begin{array}{l}\text { Before the operation, I felt light that I would be able to eat } \\
\text { normally if I had surgery. }\end{array}$ \\
\hline & \multirow{3}{*}{$\begin{array}{l}\text { Preoperative explana- } \\
\text { tion was connected } \\
\text { to eating behavior } \\
\text { through real experi- } \\
\text { ence }\end{array}$} & \multirow{2}{*}{$\begin{array}{l}\text { I remembered the explanation } \\
\text { before surgery by actually expe- } \\
\text { riencing it }\end{array}$} & I didn't understand just because I was told before surgery \\
\hline & & & $\begin{array}{l}\text { Remembering the explanation before surgery by experi- } \\
\text { encing your own experience after surgery }\end{array}$ \\
\hline & & $\begin{array}{l}\text { I was able to calmly deal with } \\
\text { it because I was listening to the } \\
\text { explanation }\end{array}$ & $\begin{array}{l}\text { Because I was listening to the explanation, I could calmly } \\
\text { deal with it }\end{array}$ \\
\hline
\end{tabular}

(3) Building In reality, things do not Had received guidance on meal self- manage- go the same way as we intake from doctors and nutriment skills in had thought terms of eating behaviors tionists many times

In reality, things do not work in accordance with what is written in manuals

Will power and self- It is necessary to have a strong control are necessary will power and to continue to for maintaining the make efforts stability of eating behaviors

\begin{abstract}
Control myself by seriously taking the precautions drawn from actual experiences

Eating still poses a risk to my life, and I must continue to exercise precautions against symptoms and poor eating behaviors for as long as I live
\end{abstract}

There is a manual, but it does not follow the manual

It 's actually impossible to do as instructed

\section{Repeated meal instruction from a doctor}

Received nutritional guidance from a dietitian

Will and effort are required to maintain eating behavior

Understanding how to eat food but not being able to sustain behavior is a weakness in one's will

\section{Self-control is needed to stay stable}

Control the precautions when eating according to the actual experience and daily physical condition

Eating is still a life-threatening

The symptoms of eating should last forever behaviors that facilitate digestion $\}$ and \{When eating out, I select how to eat or what to eat depending on the person I eat with, and try not to cause trouble at restaurants\} from their actual experiences. They learned these two eating behaviors through learning the precautions that they need to take and the means to cope with these

\section{difficulties.}

At the same time, when I experienced the symptoms of eating post-operative meals, $<$ I remembered the explanation before surgery by actually experiencing it $><$ I was able to calmly deal with it because I was listening to the explanation $>$ and \{Preoperative 


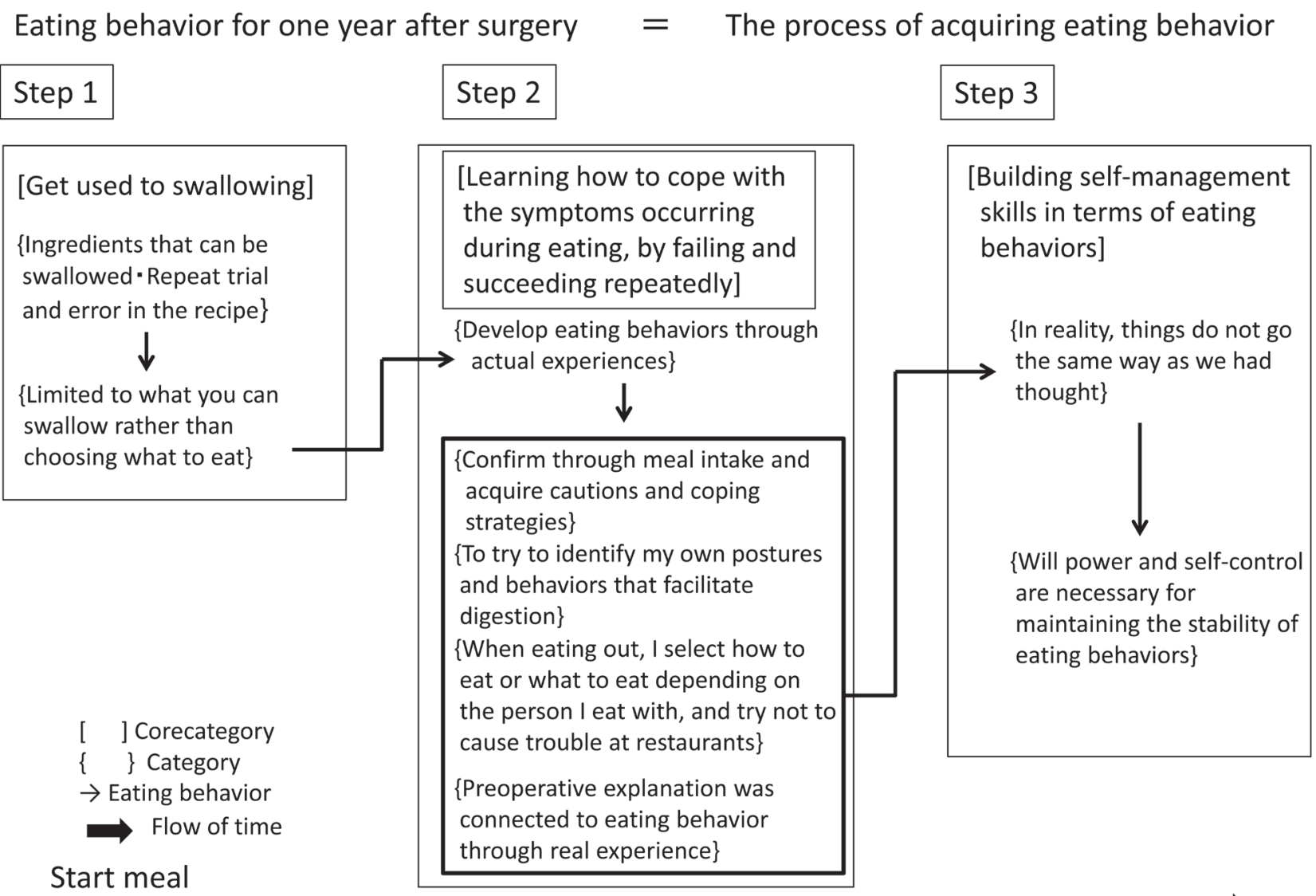

Start meal

Fig. 1. The process of acquiring postoperative eating behavior in patients with esophageal cancer.

explanation was connected to eating behavior through real experience\}.

"I can eat if I try to eat, but (if I eat a lot,), I choke or what I eat does not go down the throat into my stomach. Therefore, I always eat the same amount. (I)"

"I seldom eat out, except for very special occasions, because I cannot eat at the same pace as everyone else. (F)"

"(Before surgery) I could not pay attention to my postoperative condition, as I was preoccupied with the things that I had to do at home while getting ready for the surgery. (After resuming eating after surgery,) I recalled things like, "So, this is what my doctor told me. $(\mathrm{H})$ "

iii) Stage 3 [Building self-management skills in terms of eating behaviors]

When they resumed eating after surgery, the study subjects also realized that In reality, things do not go the same way as we had thought $\}$, by experiencing that $<$ In reality, things do not work in accordance with what is written in manuals $>$ although they $<$ Had received guidance on meal intake from doctors and nutritionists many times>.

Through actual experience, they became aware that it takes will power, and learning \{Will power and self-control are necessary for maintaining the stability of eating behaviors $\}$. They were unable to deal with symptom exacerbation when it occurred, even though they knew how to cope. This made them aware that $<$ It is necessary to have a strong will power and to continue to make efforts>, considering that it is important to $<$ Control myself by seriously taking the precautions drawn from actual experiences $>$. Thus, the postoperative study subjects developed their own postoperative eating behaviors, and realized that $<$ Eating still poses a risk to my life, and I must continue to exercise precautions against symptoms and poor eating behaviors for as long as I live>. This is the conclusion that they reached after experiencing the symptoms they had and learning how to cope with the symptoms.

"Well, when I was in good health, I could do as I wished. Now, (in order to maintain eating behaviors) I 
know it is necessary to exercise self-control. Making an effort is all that is needed. (C)" "I still face difficulties in eating. I know that this will last for as long as I live, and therefore I will keep working hard at eating and trying to identify foods that I can eat, without giving up. (J)" A diagram showing the relationship among categories (Fig. 1) After surgery, dietary intake began with resumption of oral intake, and the passage of time to present is indicated by arrows. In Step 1, under the core category of [Get used to swallowing], the study subjects realized \{Limited to what you can swallow rather than choosing what to eat $\}$ through their eating behaviors by \{Ingredients that can be swallowed - Repeat trial and error in the recipe\}. Through this experience, they moved to the Stage 2 core category of [Learning how to cope with the symptoms occurring during eating, by failing and succeeding repeatedly].

In Stage 2, focusing on \{Developing eating behaviors through actual experiences $\}$, they made efforts to develop specific eating behaviors aimed at \{Confirm through meal intake and acquire cautions and coping strategies $\}$, \{To try to identify my own postures and behaviors that facilitate digestion\}, \{When eating out, I select how to eat or what to eat depending on the person I eat with, and try not to cause trouble at restaurants $\}$ and finding that Preoperative explanation was connected to eating behavior through real experience\}. Through this process of developing specific eating behaviors by failing and succeeding repeatedly, they finally reached Stage 3 [Building self-management skills in terms of eating behaviors].

In Stage 3, there were differences in individual symptoms and also in the strategies that they used to cope with such symptoms, because they learned through actual experience that \{Will power and self-control are necessary for maintaining the stability of eating behaviors\} and through their realization that $\{$ In reality, things do not go the same way as we had thought\}.

\section{DISCUSSION}

This study was conducted to identify the eating behaviors of postoperative esophageal cancer patients during their first year after surgery. The study identified the following processes involved in the development of eating behaviors.

With regard to the symptoms that the postoperative esophageal cancer patients experience while eating, previous studies have identified the following: prolonged meal times and the fact that there are many patients who are fearful about accidental swallowing and having something becoming stuck in the throat, ${ }^{7}$ difficulties in daily lives, ${ }^{11}$ the fact that eating behaviors are far more painful in the postoperative state than they had expected. ${ }^{9}$ This is considered to be related to the difficulty in forming mental images of their state after surgery and in being mentally unprepared before the surgery despite receiving an explanation prior to surgery. ${ }^{14}$

This study identified that in Stage 1, the patients face the reality that they cannot eat in the same way as they did before at the time of resumption of oral intake. This means that prior to the surgery, they were not concerned about the postoperative symptoms occurring potentially during eating and the hardships associated with eating behaviors.

Takeda reported that neglecting the recognition or trial-and-error activity using the five senses leads to separation between reality and concept, disabling the ability of people to understand semantic principles. Takeda states that the ultimate evidence comes from confirmation obtained through experience, that is, by using the whole body and mind. ${ }^{15}$ From this standpoint, it is considered that when the study subjects realized that the eating behaviors in their eating behaviors after resuming oral intake, their troubles with the eating surface became evident. Therefore, for these patients, the eating difficulties that they experienced after the surgery were different from those that they expected and were therefore harder to bear.

In this situation, the process of [Becoming accustomed to swallowing] is considered as their first experience of eating behaviors that they experience and represents the time when they face the reality for the first time.

In the Stage 2, which represents [Learning how to cope with the symptoms occurring during eating, by failing and succeeding repeatedly], the patients are considered to become aware of the necessity that they need to change their eating behaviors as a result of their self-evaluation and experience of their symptoms and behaviors during eating. This awareness is considered to be drawn from the fact that their behaviors, being uncontrollable by themselves, led to the exacerbation of symptoms occurring during eating.

Upon experiencing an event that makes a person strongly unpleasant and which the person has not predicted will occur to him/her, he/she evaluates the event as a threat. As a result, they bring a big change to himself/herself. ${ }^{16}$ Based on this concept, the challenge faced by a patient to develop new eating behaviors is considered to result from his/her evaluation that the painful experience arises as a result of his/her own eating behaviors.

The patient accumulated learning about his or her own eating behavior by repeating the actual experiences 
of eating behaviors. Faced with the problems that became apparent after surgery, I realized that I had no choice but to accept changes in my body, and eventually stepped up to stage 3 [Building self-management skills in terms of eating behaviors]. I think. Tokieda stated that it is important to set a "purpose for behavior control" in order to control behavior, and it can be evaluated as a solid statement to achieve that purpose. ${ }^{16}$ Young also found that making meaningful decisions requires grounds for meaningful behavior and deepens experiential learning to clarify criteria. ${ }^{17}$ From this, esophageal cancer patients accept the purpose of eating behavior as eating behavior to maintain life, and controlling their own eating behavior for that specific purpose maintains stable eating behavior. I think that I have decided that it is necessary to continue.

In past research, while restraining one's own behavior, it is said that restraining habitual behaviors and patience are harder to learn and more difficult to maintain than newly inducing more adaptive behavior. ${ }^{18}$ Therefore, it is difficult for patients to acquire and maintain new eating habits, which have been a custom for decades before surgery, and to maintain them. However, it is speculated that after the postoperative three-step process, they accepted the changes in their bodies and changed their behaviors to maintain life. As it is said that directing people to new learning opportunities can be a means to enable them to overcome the past, ${ }^{19}$ even in situations where the patients had difficulties in developing new eating behaviors, they underwent a trialand-error process as actual experience, and only then accepted the postoperative physical changes and the changes in their goals in respect of the eating behaviors. As a result, they succeeded in developing new eating behaviors.

The patient's postoperative course of esophageal cancer takes a while until stable eating behavior is achieved. Therefore, the medical practitioner not only provides professional knowledge, but also reflects on the patient's experience and feeds it back so that the patient can recognize the changed body, the individual symptoms, and eating behaviors. It is necessary to continue to support them by understanding their feeling of difficulty.

Although this study constructed a theory based on the experience of patients, it is necessary to seek objective knowledge in order to increase the truth.

The authors declare no conflict of interest.

\section{REFERENCES}

1 [Japanese Esophageal Society, Esophageal cancer diagnosis Treatment guidelines]. 4th ed. Tokyo: Kanehara Shuppan; 2017. Japanese.

2 Tsubosa Y. [Current surgical treatment and perspectives for esophageal cancer]. Nihon Shokakibyo Gakkai Zasshi. 2014;111:269-75. Japanese. PMID: 24500316

3 Tou Y, Ogaki K, Ikeda O. [Recyrrent laryngeal nerve palsy due to surgery, device for avoidance and countermeasures when it occurs]. Nippon Kikan Shokudoka Gakkai kaiho. 2009;60:128-30. Japanese.

4 Mariette C, De Botton ML, Piessen G. Surgery in esophageal and gastric cancer patients: what is the role for nutrition support in your daily practice? Ann Surg Oncol. 2012;19:212834. DOI: 10.1245/s10434-012-2225-6, PMID: 22322948

5 Shen O, Wang J, Li W, Yi W, Wang W. Assessment of healthrelated quality of life of patients with esophageal squamous cell carcinoma following esophagectomy using EORTC quality of life questionnaires. Mol Clin Oncol. 2015;3:133-8. DOI: 10.3892/mco.2014.434, PMID: 25469283

6 Tatematsu N, Hasegawa S, Tanaka E, Sakai Y, Tsuboyama T. Impact of oesophagectomy on physical fitness and healthrelated quality of life in patients with oesophageal cancer. Eur J Cancer Care (Engl). 2013;22:308-13. DOI: 10.1111/ ecc.12030, PMID: 23252510

7 van der Schaaf M, Rutegård M, Lagergren P. The influence of surgical factors on persisting symptoms 3 years after esophageal cancer surgery: a population-based study in Sweden. Ann Surg Oncol. 2013;20:1639-45. DOI: 10.1245/s10434-0122690-y, PMID: 23271489

8 Chang YL, Tsai YF, Wu YC, Hsieh MJ. Factors relating to quality of life after esophagiectomy for cancer patients in Taiwan. Cacer nurs. 2014;37:4-13.

9 Miura M, Inoue T. [Examination of food reacquisition and nursing support for esophageal cancer patients undergoing esophageal reconstruction with three-region lymphadenectomy]. Nihon Gan Kango Gakkaishi. 2007;21:14-22. Japanese.

10 Ha S, Kim K, Kim J. The influence of symptoms on quality of life among patients who have undergone oesophageal cancer surgery. Eur J Oncol Nurs. 2016;24:13-9. DOI: 10.1016/ j.ejon.2016.08.002, PMID: 27697272

11 Iino K, Watanuki N. [Analysis of nursing care for outpatients after thoracic esophageal cancer surgery]. Palliative Care Research. 2014;9:110-7. Japanese.

12 Iino K, Watanuki S, Koyama Y, Kurihara M, Ichikawa C, Okada $\mathrm{K}$, et al. Content analysis of nurses' interventions for post thoracic esophagectomy cancer patients at the outpatient clinic. Palliative Care Research. 2014;9:110-7. DOI: 10.2512/ jspm.9.110 Japanese.

13 Mori K, Akimoto N. [Research on life difficulties and management of patients who underwent esophagectmy for esophageal cancer]. Okayama Daigaku Igakubu Hoken Gakka Kiyo. 2005;16:39-48. Japanese.

14 Nishimura K. [Impact on life after early esophagectomy and post-thoracic reconstruction for early esophageal cancer patients]. Nihon Gan Kango Gakkaishi. 2013;27:65-72. Japanese.

15 Takeda Y. [Informed knowledge and knowledge of the whole body] [Internet]. Tokyo: Shirakaba Kyoikukan; 2014 [cited 2018 Feb 20]. Available from http://www.shirakaba.gr.jp/ large_sources/contents/. Japanese.

16 Fukuzi T. [Elephant tail]. Tokyo: Shinpusha; 2005. Japanese. 
17 Young M. [The mystery of the Espritan: Development of psychoanalytic skills Art \& Philosophy Class; Foundation building] [Internet]. Goldy Ltd; [updated 2017 Sep; cited 2018 Feb 20]. Available from: https://www.mearts.com/ Japanese.
18 Sugiwaka H. [If you would like to do it: self-control and clinical psychology]. Doshisha Clinical Psychology: therapy and research. 2011;1:17-20. Japanese.

19 Kamijo N, Yukawa S. [Features and implications of stressful events]. Nihon Shinrin Gakkaishi. 2013;77:379. Japanese. 